\title{
How large-scale subsidence affects stratocumulus transitions
}

\author{
J. J. van der Dussen ${ }^{1}$, S. R. de Roode ${ }^{1}$, and A. P. Siebesma ${ }^{2,1}$ \\ ${ }^{1}$ Department of Geoscience and Remote Sensing, Delft University of Technology, Delft, the Netherlands \\ ${ }^{2}$ Royal Netherlands Meteorological Institute (KNMI), De Bilt, the Netherlands
}

Correspondence to: J. J. van der Dussen (johanvanderdussen@outlook.com)

Received: 18 May 2015 - Published in Atmos. Chem. Phys. Discuss.: 24 June 2015

Revised: 14 December 2015 - Accepted: 16 December 2015 - Published: 21 January 2016

\begin{abstract}
Some climate modeling results suggest that the Hadley circulation might weaken in a future climate, causing a subsequent reduction in the large-scale subsidence velocity in the subtropics. In this study we analyze the cloud liquid water path (LWP) budget from large-eddy simulation (LES) results of three idealized stratocumulus transition cases, each with a different subsidence rate. As shown in previous studies a reduced subsidence is found to lead to a deeper stratocumulus-topped boundary layer, an enhanced cloud-top entrainment rate and a delay in the transition of stratocumulus clouds into shallow cumulus clouds during its equatorwards advection by the prevailing trade winds. The effect of a reduction of the subsidence rate can be summarized as follows. The initial deepening of the stratocumulus layer is partly counteracted by an enhanced absorption of solar radiation. After some hours the deepening of the boundary layer is accelerated by an enhancement of the entrainment rate. Because this is accompanied by a change in the cloudbase turbulent fluxes of moisture and heat, the net change in the LWP due to changes in the turbulent flux profiles is negligibly small.
\end{abstract}

\section{Introduction}

As subtropical marine stratocumulus clouds are advected by the tradewinds over increasingly warm water they are often observed to transition into shallow cumulus clouds. Such transitions involve a rapid decrease of the cloud cover and the cooling effect due to the presence of low clouds is hence diminished. Therefore, a change of the pace of stratocumulus transitions in a future climate could potentially be of importance for the magnitude of the cloud-climate feedback.
Some general circulation model results suggest that the Hadley-Walker cell may weaken as a result of climate warming (e.g. Held and Soden, 2006; Vecchi and Soden, 2007). In the subtropical part of the Hadley cell there is a mean subsiding motion of air, which is schematically shown in Fig. 1. It is therefore reasonable to assume that the large-scale subsidence in subtropical areas will weaken in a future climate.

Large-eddy simulation (LES) results and mixed-layer model studies show that for fixed large-scale conditions such as the sea surface temperature and the horizontal wind speed, a reduction of the large-scale subsidence causes the stratocumulus steady-state liquid water path (LWP) to increase (e.g. Bretherton et al., 2013; De Roode et al., 2014). As such, reduced subsidence might be one of the few processes to cause additional cloudiness in a future climate scenario (Bretherton and Blossey, 2014). It is therefore of paramount importance to have a thorough understanding of how a weakening of the large-scale subsidence increases the LWP and the lifetime of stratocumulus clouds.

Together with the entrainment rate, the subsidence velocity determines the rate of deepening of boundary layers that are capped by an inversion, as follows

$\frac{\mathrm{d} z_{\mathrm{i}}}{\mathrm{d} t}=w_{\mathrm{e}}+\bar{w}\left(z_{\mathrm{i}}\right)$.

Here, $z_{\mathrm{i}}$ is the height of the inversion, $t$ is time, $w_{\mathrm{e}}$ is the entrainment velocity and $\bar{w}$ is the large-scale subsidence velocity. A lower subsidence velocity would therefore lead to a more rapid deepening of the boundary layer if the entrainment velocity would remain unaffected. This deepening would increase decoupling of the boundary layer (Park et al., 2004; Wood and Bretherton, 2004) and therefore it was hypothesized that weaker subsidence would increase the pace of stratocumulus transitions (e.g. Wyant et al., 1997; Bretherton et al., 1999). 


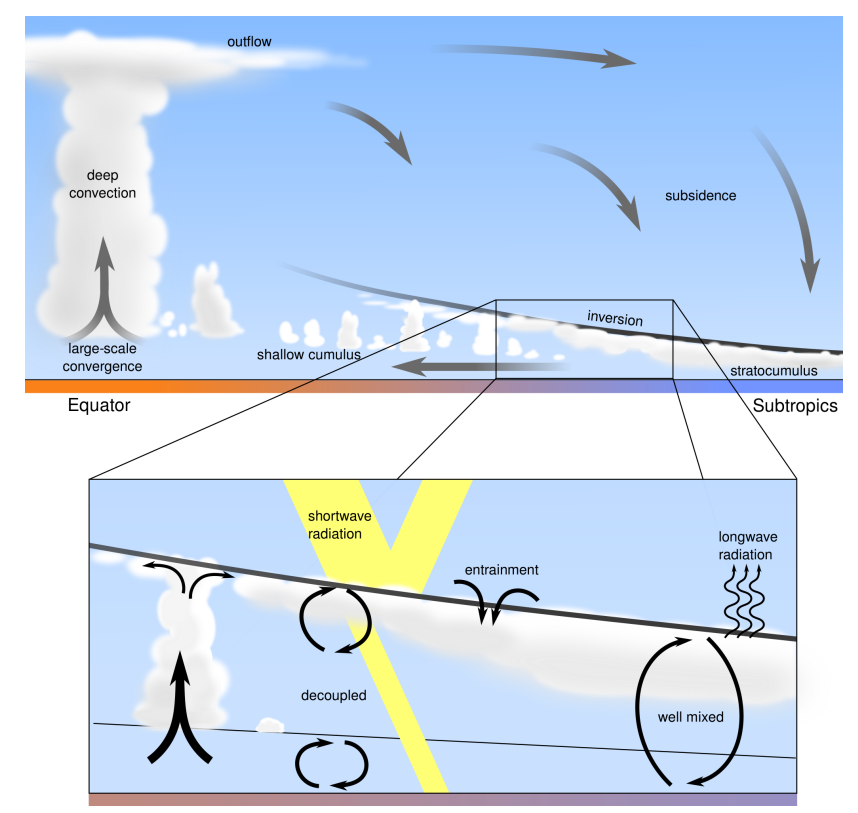

Figure 1. A schematic representation of the Hadley circulation and the cloud types that typically occur within this large-scale circulation (after Arakawa, 1975; Emanuel, 1994). The bottom panel zooms in on the stratocumulus transition regime within the Hadley circulation.

Svensson et al. (2000), however, used a one-dimensional turbulence model to show that the moment of break up of the stratocumulus layer is actually delayed when the magnitude of the large-scale subsidence velocity is decreased. Myers and Norris (2013) corroborated this finding by showing from observations that low cloud amount in the subtropics tends to decrease as subsidence becomes stronger. Moreover, Sandu and Stevens (2011) performed several LESs of stratocumulus transition cases and found that although the entrainment rate increased in the sensitivity run with reduced subsidence, the larger entrainment drying and warming trend of the boundary layer did apparently not lead to a more rapid cloud break up. To shed some light on this finding, a budget equation for the tendency of the LWP of the stratocumulus layer as derived by Van der Dussen et al. (2014) is used to analyze results of idealized LESs in order to determine the role of each individual physical process during stratocumulus transitions. Through this analysis, insight is gained into how subsidence affects the pace of stratocumulus transitions, which helps to determine the robustness of the sign of the response of stratocumulus clouds to a weakening subsidence.

The LES results provide complete information on entrainment rate and subsidence velocity, in contrast to observations or reanalysis products in which these variables are typically poorly constrained (Bretherton et al., 1995; De Roode and Duynkerke, 1997; Ciesielski et al., 2001; Carman et al., 2012; Duynkerke et al., 1999). As discussed by Bretherton (2015), turbulence-resolving LES models using sub-100 m grid spacings over small computational domains are very suitable tools to study low cloud regimes such as stratocumulus and shallow cumulus.

The main aim of this study is to better understand the prolonged lifetime of stratocumulus during its Lagrangian advection over increasing SSTs in case the subsidence is reduced and despite the fact that the entrainment warming and drying effect is enhanced. In the next section, first the methodology is explained, which is used to assess the relative importance of each physical process that is involved in the evolution of stratocumulus-topped boundary layers. In Sect. 3 the details of the LESs that have been performed are described. The LWP tendency during the ASTEX transition is analyzed in Sect. 4, while several sensitivity studies are discussed in Sect. 5. In the final section, a short summary of the conclusions is presented.

\section{Methodology}

\subsection{Contributions to the LWP tendency}

The LWP of an adiabatic stratocumulus cloud is here defined as

$\mathrm{LWP}=\int_{z=0}^{\infty} \rho q_{1} \mathrm{~d} z$,

where $q_{1}$ is the liquid water specific humidity, which is the sum of the cloud water $q_{\mathrm{c}}$ and rain water specific humidity $q_{\mathrm{r}}$. Furthermore, $\rho$ is the density of air and $z$ is height. Van der Dussen et al. (2014) extended the LWP budget analysis of Randall et al. (1984) by including the contribution of cloud-base turbulent fluxes, radiation and drizzle, in addition to entrainment. An LWP tendency equation was derived on the basis of the budget equations for heat, water and mass and allows for the quantification of the contribution of individual physical processes to the LWP tendency, so

$\frac{\partial \mathrm{LWP}}{\partial t}=\mathrm{Ent}+$ Base + Rad + Prec + Subs.

Here, the abbreviations indicate LWP tendencies as a result of entrainment of free tropospheric air into the boundary layer at the top of the stratocumulus layer (Ent), turbulent fluxes of total specific humidity $q_{\mathrm{t}}$ and liquid water potential temperature $\theta_{1}$ at the base of the stratocumulus layer (Base), divergence of the net radiative flux over the stratocumulus layer (Rad), divergence of the precipitation flux over the stratocumulus layer (Prec) and large-scale subsidence (Subs). We refer to Van der Dussen et al. (2014) for a derivation of these terms. Below, the results are repeated for convenience.

The LWP tendency due to large-scale subsidence can be written as

Subs $=-\rho h \Gamma_{q_{1}} \bar{w}\left(z_{\mathrm{i}}\right)$, 
in which $h$ is the thickness of the stratocumulus cloud layer, $\bar{w}$ is the large-scale vertical velocity and $\Gamma_{q_{1}}=-\partial q_{1} / \partial z<0$ is the lapse rate of $q_{1}$. Following Van der Dussen et al. (2014), the value of $\Gamma_{q_{1}}$ is approximated by assuming a moist adiabatic temperature lapse rate. As the stratocumulus cloud layer is typically vertically well-mixed, this is in good agreement with the actual value of $\Gamma_{q_{1}}$ that can be obtained from the vertical profile of $q_{1}$. We define the inversion height $z_{\mathrm{i}}$ as the top of the inversion layer, $z_{i}^{+}$, since the evaluation of the turbulent fluxes at this height results in the best closure of the LWP budget as discussed in Sect. 2.2. The inversion layer is usually only several tens of meters thick, so this somewhat unconventional definition of $z_{i}$ has negligible impact on the remaining terms in the budget. Equation (4) shows that subsidence acts to decrease the LWP by pushing the stratocumulus cloud top down.

Note that all variables used in the current study are slabaverages unless specifically stated otherwise. The overbar that is commonly used to indicate a slab-averaged variable is omitted for notational convenience, except for the turbulent fluxes and variances.

The entrainment contribution to the LWP tendency is as follows:

Ent $=\rho w_{\mathrm{e}}\left(\eta \Delta q_{\mathrm{t}}-\Pi \gamma \eta \Delta \theta_{\mathrm{l}}-h \Gamma_{q_{\mathrm{l}}}\right)$,

where $\Delta q_{\mathrm{t}}$ and $\Delta \theta_{\mathrm{l}}$ indicate the inversion jumps of $q_{\mathrm{t}}$ and $\theta_{1}$ respectively, $\Pi$ is the Exner function and $\gamma=\partial q_{\mathrm{s}} / \partial T \approx$ $0.55 \mathrm{~g} \mathrm{~kg}^{-1} \mathrm{~K}^{-1}$ is described by the Clausius-Clapeyron relation. Furthermore, $\eta$ is a thermodynamic factor that depends mainly on temperature and is given by

$\eta=\left(1+\frac{L_{\mathrm{v}} \gamma}{c_{p}}\right)^{-1} \approx 0.4$

with $c_{p}$ the specific heat of air at constant pressure and $L_{\mathrm{V}}$ the latent heat of vaporization. The entrainment rate $w_{\mathrm{e}}$ is determined from the diagnosed time evolution of the inversion height and the prescribed subsidence at the inversion height using Eq. (1).

The remaining three terms of Eq. (3) are

Base $=\rho \eta\left[\overline{w^{\prime} q_{\mathrm{t}}^{\prime}}\left(z_{\mathrm{b}}\right)-\Pi \gamma \overline{w^{\prime} \theta_{1}^{\prime}}\left(z_{\mathrm{b}}\right)\right]$

$\operatorname{Rad}=\frac{\eta \gamma}{c_{p}}\left[F_{\mathrm{rad}}\left(z_{\mathrm{t}}\right)-F_{\mathrm{rad}}\left(z_{\mathrm{b}}\right)\right]$

Prec $=-\rho\left[P\left(z_{\mathrm{t}}\right)-P\left(z_{\mathrm{b}}\right)\right]$.

Here, $\overline{w^{\prime} q_{\mathrm{t}}^{\prime}}$ and $\overline{w^{\prime} \theta_{1}^{\prime}}$ are the turbulent fluxes of $q_{\mathrm{t}}$ and $\theta_{\mathrm{l}}$. Furthermore, $z_{\mathrm{b}}$ and $z_{\mathrm{t}}$ are stratocumulus base and top height, respectively. Furthermore, $F_{\text {rad }}$ is the radiation flux in $\mathrm{W} \mathrm{m}^{-2}$ and $P$ is the precipitation flux in $\mathrm{m} \mathrm{s}^{-1}$, both of which are defined negative downward.

\subsection{Evaluation of cloud boundaries}

The LWP budget equation described in the previous section is used to quantify the relative importance of the individual physical processes to the total LWP tendency. To this end, Eqs. (4)-(8) will be evaluated using slab-averaged vertical profiles derived from the LES. To accurately evaluate the LWP tendencies with this method, it is important to properly define the top and bottom interfaces of the stratocumulus layer.

The stratocumulus base height is defined as the minimum height where the slab-averaged cloud fraction $c_{\mathrm{f}}$ exceeds 0.4 ,

$z_{\mathrm{b}}=\min (z), \quad$ where $\quad c_{\mathrm{f}}(z)>0.4$.

Here $c_{\mathrm{f}}(z)$ is the fraction of grid cells in a horizontal slab at height $z$ for which $q_{\mathrm{c}}>0$. Note that this definition excludes the presence of rain water. The criterion in Eq. (9) selects the stratocumulus cloud base height, and excludes the effect of cumulus clouds which can have their base well below the stratocumulus layer. The analysis is quite insensitive to the critical $c_{\mathrm{f}}$ value as stratocumulus base height is typically well defined in terms of the cloud fraction profile. We have tested different values for the criterion, and found that any value between 0.2 and 0.8 can be used to get a good correspondence between the diagnosed LWP tendency from the terms on the rhs of Eq. (3) and the tendency as diagnosed directly from the LES cloud fields.

Some more care is required for the definition of stratocumulus top height $z_{\mathrm{t}}$. To take into account the vertical undulations in the cloud top and in particular its effect on the horizontal slab mean flux profiles (vanZanten et al., 1999), the budget analysis is performed up to the top of the inversion layer, the height of which is defined as $z_{i}^{+}$. Hence, in Eq. (7)

$z_{\mathrm{t}}=z_{\mathrm{i}}^{+}$

There is practically no cloud water at this level, so that the precipitation flux is negligible, $P\left(z_{\mathrm{t}}\right) \approx 0$.

The lower and upper boundaries of the inversion layer are determined on the basis of the profile of the variance of $\theta_{1}$ as follows (Yamaguchi et al., 2011):

$$
\begin{aligned}
& z_{\mathrm{i}}^{+}=z, \quad \text { where } \overline{\theta_{1}^{\prime 2}}=0.05 \cdot \max \left(\overline{\theta_{1}^{\prime 2}}\right) \\
& \quad \text { and } \quad z>z_{\max }, \\
& z_{\mathrm{i}}^{-}=z, \quad \text { where } \overline{\theta_{1}^{\prime 2}}=0.05 \cdot \max \left(\overline{\theta_{1}^{\prime 2}}\right) \\
& \quad \text { and } \quad z<z_{\max } .
\end{aligned}
$$

Here, $z_{\max }$ is the height at which the maximum of the $\overline{\theta_{1}^{\prime 2}}$ profile is located. Linear interpolation is used between the grid levels to determine $z_{i}^{+}$and $z_{i}^{-}$. The peak of the slabaveraged $\overline{{\theta_{1}^{\prime 2}}^{2}}$ profile is very well defined so that the values of $z_{\mathrm{i}}^{+}$and $z_{\mathrm{i}}^{-}$hardly depend on the rather arbitrary criteria in Eqs. (11a) and (11b). 
The inversion jump of a conserved variable $\varphi$ is defined as the difference between the variable at the top and at the base of the inversion layer

$$
\Delta \varphi=\varphi\left(z_{\mathrm{i}}^{+}\right)-\varphi\left(z_{\mathrm{i}}^{-}\right) .
$$

\section{Setup}

\subsection{Forcings and domain}

In Sect. 4 the LWP budget of the Atlantic Stratocumulus Transition Experiment (ASTEX, Albrecht et al., 1995) case is analyzed, for which the initial conditions and forcings were described by Van der Dussen et al. (2013). The simulation lasts $40 \mathrm{~h}$ and features diurnally varying insolation. During the transition, the boundary layer evolves from relatively shallow and well mixed to deep and decoupled with cumulus updrafts underneath a thin broken stratocumulus layer. The results of this case are used here to illustrate how the methodology described in the previous section can help to understand the often complex interaction between processes that together determine the evolution of the stratocumulus layer.

Many of the forcings and boundary conditions for the ASTEX case, such as the subsidence velocity, the solar zenith angle and the geostrophic wind velocities, vary with time. This could make the interpretation of sensitivity experiments unnecessarily complicated. The forcings of the ASTEX case have therefore been idealized for the sensitivity experiments, as follows.

A diurnally averaged solar zenith angle of $68.72^{\circ}$ is prescribed, resulting in a constant downwelling shortwave radiative flux of approximately $494 \mathrm{~W} \mathrm{~m}^{-2}$ at the top of the atmosphere. Furthermore, the geostrophic wind velocities are kept constant and equal to the initial horizontal velocities, which are constant with height at $(u, v)=(5.5,0) \mathrm{m} \mathrm{s}^{-1}$. Hence, the mean wind speed is approximately constant in time. The microphysics parameterization scheme is disabled.

For the sensitivity simulations, the prescribed large-scale subsidence profile is kept constant with time. It is defined as

$\bar{w}(z)= \begin{cases}-D z & \text { for } z \leq z_{D} \\ -D z_{D} & \text { otherwise, }\end{cases}$

where $z_{D}=500 \mathrm{~m}$ and $D$ is the large-scale divergence of horizontal winds. The only boundary condition that varies in time is the SST, which increases linearly from 291 to $297 \mathrm{~K}$ over the course of the 60-hour simulations.

The horizontal domain size is $4800 \times 4800 \mathrm{~m}^{2}$, divided into $192 \times 192$ gridpoints that are spaced $25 \mathrm{~m}$ apart. In the vertical direction, the resolution is varied from $10 \mathrm{~m}$ at the surface to $5 \mathrm{~m}$ for $z$ between 500 and $2300 \mathrm{~m}$. Above, the vertical grid spacing is increased by $5 \%$ per level up to a height of $3 \mathrm{~km}$, resulting in a total of 500 levels.
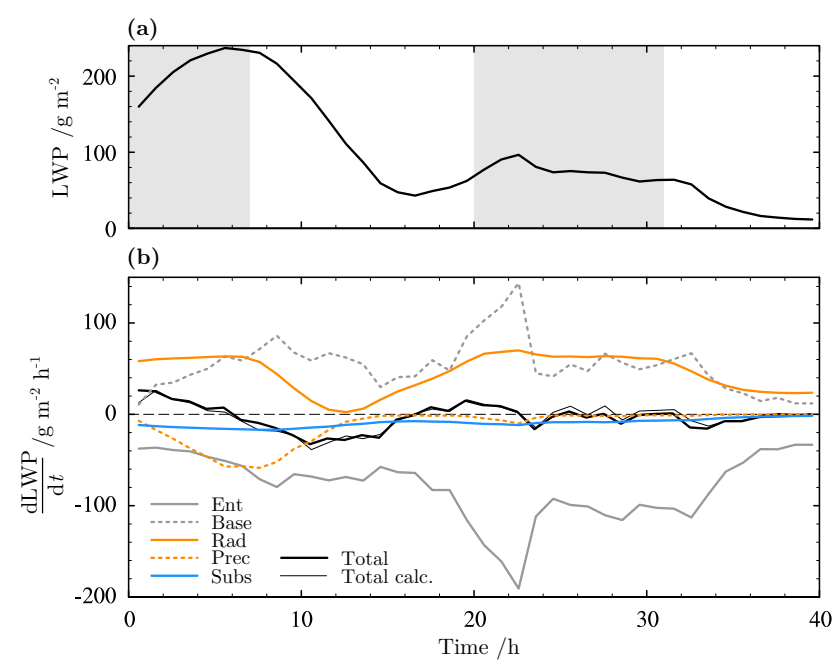

Figure 2. (a) The LWP as a function of time for the ASTEX transition simulation. The gray shaded areas indicate nighttime conditions. (b) The tendency of the LWP as a function of time, split into the contributions from the individual physical processes according to Eq. (3). Line colors and styles according to the legend. The horizontal dashed black line indicates the zero tendency level as a reference.

\subsection{Model details}

The Dutch Atmospheric LES (DALES) model version 4.0 (Heus et al., 2010; Böing, 2014) was used to perform the simulations in this study. This model features among others an anelastic core, fifth-order hybrid weighted essentially nonoscillatory advection (Jiang and Shu, 1996; Blossey and Durran, 2008), the RRTMG scheme for radiation (Iacono et al., 2008), bulk microphysics (Kogan, 2013) and subgrid-scale turbulence following Deardorff (1980). The model version and settings are identical to those used by Van der Dussen et al. (2015).

\section{ASTEX transition}

The LWP for the ASTEX case is shown in Fig. 2a as a function of time. The LWP evolution is qualitatively similar to that obtained with DALES version 3.2 (Van der Dussen et al., 2013), despite the fact that different radiation and microphysics parameterization schemes are used in the present study.

The tendency of the LWP is indicated by the thick black line in Fig. 2b. The thin black line in this figure shows the net LWP tendency diagnosed using Eq. (3), which agrees very well with the actual LWP tendency. Note that in the discussion below we will loosely refer to a negative LWP tendency as a thinning of the stratocumulus layer, as the LWP is closely related to the cloud thickness as long as the cloud cover is unity. Because the stratocumulus cloud decks we are inves- 
tigating are vertically well mixed, the LWP is approximately proportional to the cloud layer depth squared (Albrecht et al., 1990). Ghonima et al. (2015) actually demonstrated that the LWP budget and the tendency equation for the cloud layer thickness derived by Wood (2007) are analogous.

Interestingly, the net LWP tendency is small as compared to the contributions from entrainment, radiation and turbulent fluxes at stratocumulus base height. The simulation starts approximately at midnight. During the initial $8 \mathrm{~h}$, the contribution of the radiation to the LWP tendency is therefore solely due to longwave radiative cooling. This contribution amounts roughly to $60 \mathrm{~g} \mathrm{~m}^{-2} \mathrm{~h}^{-1}$ and causes the stratocumulus layer to thicken.

The increase of the LWP triggers additional precipitation, so that its thinning contribution increases until it approximately balances the radiative tendency and the net LWP tendency decreases.

The sun rises after about $8 \mathrm{~h}$ of simulation. The stratocumulus layer absorbs a fraction of the incident solar radiation, which causes a warming tendency that partly offsets the longwave radiative cooling of the cloud. Therefore, the net cloud thickening effect due to radiation diminishes during the day. This has a pronounced effect on the total LWP tendency, which becomes negative leading to the sharp decrease of the LWP as shown in Fig. 2a. As the LWP decreases, the stratocumulus layer produces less precipitation, so that the thinning tendency due to precipitation reduces to approximately zero after about $14 \mathrm{~h}$. This shows that the feedback of the LWP on the generation of precipitation acts as a buffering mechanism that levels out variations of the LWP on timescales of several hours.

The decrease of the net radiative cooling during the day also diminishes the production of turbulence in the cloud layer. This is reflected by a weakening of the Ent and Base terms in Fig. $2 b$ that are both turbulence driven. Interestingly, the response of the turbulence intensity to the change of the radiative forcing is delayed by several hours, which is particularly clear for the Base term. As a result, the minimum LWP in Fig. 2a occurs about two to 4 hours after local noon.

The Ent and Base terms in Fig. 2b are strongly anticorrelated, which is made particularly clear by the peaks that occur for both terms after approximately $22 \mathrm{~h}$. The magnitudes of these turbulence-driven tendencies are approximately equal during the first half of the simulation, so that they cancel to a large extent. The Base term remains roughly constant throughout most of the simulation suggesting that decoupling of the boundary layer does not significantly affect the transport of humidity to the stratocumulus cloud. The magnitude of the entrainment term, on the other hand, continues to increase throughout most of the simulation so that it becomes almost twice as large as the Base term during the second half of the transition. This can be explained from the magnitude of $\Delta q_{\mathrm{t}}$ that gradually increases by the combined effects of the increasing sea surface temperature and large-scale subsi-
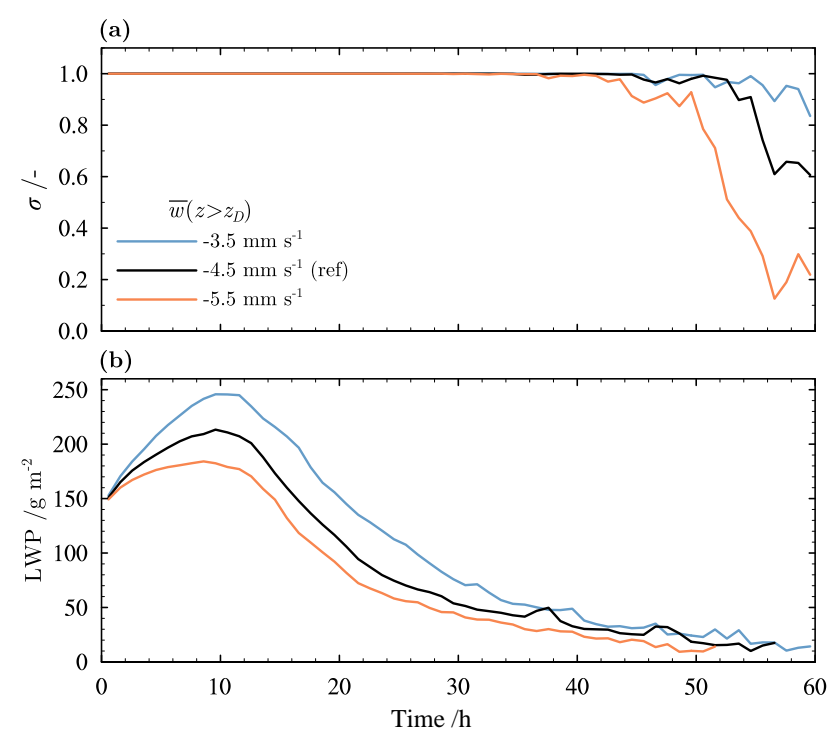

Figure 3. (a) The projected cloud cover $\sigma$ and (b) the LWP as a function of time for the sensitivity simulations in which the largescale subsidence velocity is varied as indicated by the legend.

dence that slowly dries the free troposphere (Van der Dussen et al., 2014).

The contribution of the large-scale subsidence to the LWP is relatively small and negative. Its thinning effect becomes weaker as the stratocumulus cloud thins, which is due to the $h$ dependence in Eq. (4).

During the second night, after about $20 \mathrm{~h}$, the thinning due to entrainment is approximately balanced by equal thickening contributions by the radiative cooling and the fluxes at cloud base. At this stage the LWP has become low, resulting in little precipitation and hence a negligible drying tendency due to precipitation. As a result the LWP decreases only very slightly until the cloud layer starts to break up at the beginning of the second day.

\section{Sensitivity to the large-scale subsidence}

\subsection{Effect on cloud properties}

Figure 3a shows the projected cloud cover $\sigma$, defined as the fraction of LES vertical subcolumns with $q_{\mathrm{c}}>0$, for the three sensitivity simulations in which the large-scale subsidence velocity is varied. The results demonstrate clearly that a weakening of the large-scale subsidence extends the lifetime of the stratocumulus layer, thereby corroborating the findings of Svensson et al. (2000) and Sandu and Stevens (2011). Figure $3 \mathrm{~b}$ furthermore shows that a weakening of the subsidence causes the LWP to increase. The large differences among the simulations are somewhat puzzling, as it was shown in the previous section that the contribution of subsidence to the LWP tendency is relatively small. 

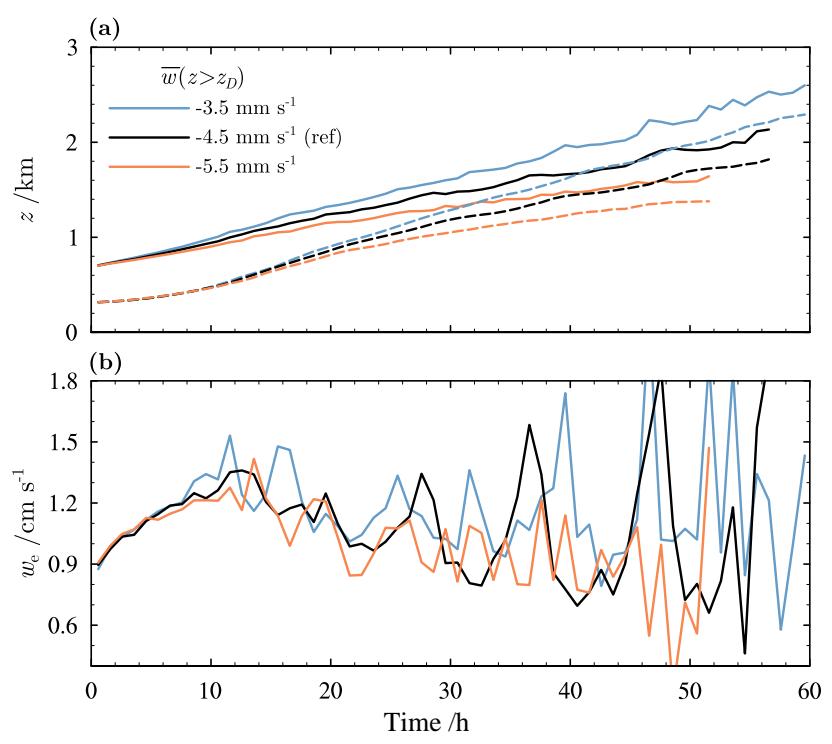

Figure 4. (a) The stratocumulus top (solid) and base height (dashed) and (b) the entrainment velocity as a function of time for the subsidence sensitivity simulations.

Despite the absence of precipitation and a diurnal cycle, the transitions with the idealized forcings are qualitatively similar to the original ASTEX transition (Fig. 2a). A prominent difference however is the moment of stratocumulus breakup, which occurs approximately $10 \mathrm{~h}$ earlier in the original ASTEX transition. As a possible explanation this is most likely due to the magnitude of the horizontal wind that decreases in the second half of this transition and causes a drastic reduction of the surface humidity flux. In the sensitivity experiments, on the other hand, the horizontal wind speed is constant in time possibly leading to a greater moisture supply to the stratocumulus layer, which prolongs its lifetime. The latent heat flux results of our idealized LES sensitivity experiments are consistent with a recent model intercomparison study on Lagrangian stratocumulus transitions (De Roode et al., 2016), which explains that for a constant wind speed and a linearly increasing SST with time the LHF should increase exponentially with time.

Figure $4 \mathrm{a}$ shows the top and base interfaces of the stratocumulus layer as defined in Sect. 2.2. Differences in stratocumulus top height start to occur soon after the start of the simulations. Stratocumulus base height, on the other hand, remains unaffected for roughly $15 \mathrm{~h}$. This suggests that the difference in the subsidence velocity does not strongly affect the temperature and humidity profiles in the bulk of the boundary layer during this period. Later on in the simulations the stratocumulus cloud bases start to diverge.

It is important to note that the differences of the inversion height among the simulations are roughly a factor of two larger than would be expected on the basis of the difference in the subsidence rate alone. As can be seen in Fig. 4b,
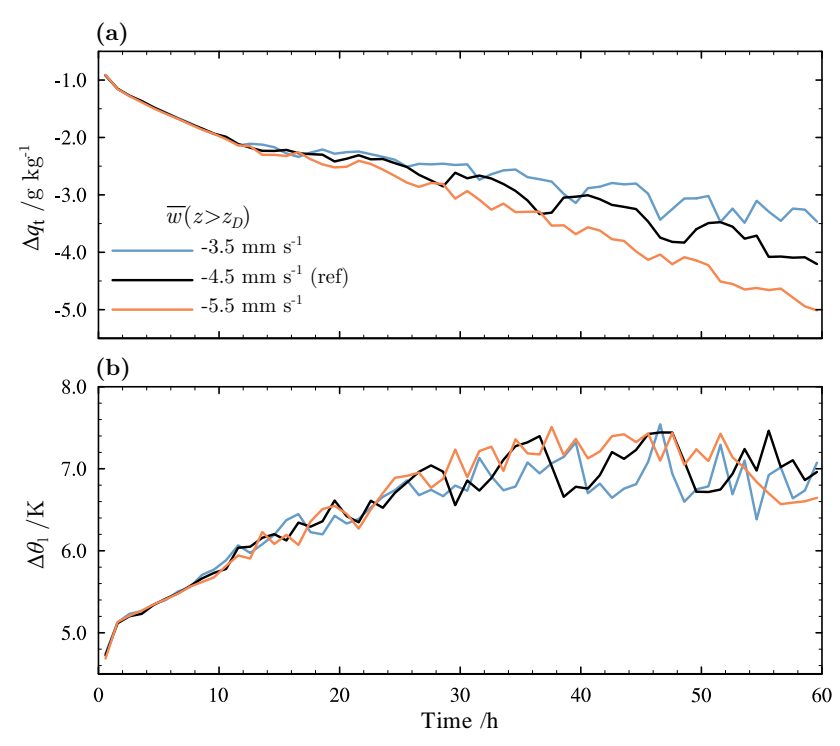

Figure 5. The inversion jumps (a) of total humidity $\Delta q_{\mathrm{t}}$ and (b) of liquid water potential temperature $\Delta \theta_{1}$ as a function of time for each of the sensitivity experiments.

the entrainment rate is found to increase as subsidence weakens. Such an increase was also found by Sandu and Stevens (2011) and it is most likely the result of the larger LWP (see Fig. 3b). This typically causes the cloud layer to be more energetic eventually leading to enhanced entrainment (Nicholls and Turton, 1986; Jones et al., 2014).

The inversion strength, as measured by $\Delta \theta_{1}$, is hardly affected by the change of the subsidence rate as is shown in Fig. $5 b$, because the change of $\theta_{1}$ is about as large in the cloud layer as in the free troposphere. The differences in the entrainment rate therefore can not be explained by changes of the inversion strength. This is somewhat unexpected as large-scale subsidence and lower tropospheric stability are positively correlated at longer time-scales (e.g. Myers and Norris, 2013).

\subsection{Analysis of LWP budget}

To determine how much each of the physical processes that affect the LWP contribute to the LWP differences among the simulations, the terms of the LWP budget equation are shown individually in the left column of Fig. 6. Note that the scale of the vertical axis of the subfigures varies significantly.

Figure 6a shows the LWP tendency due to subsidence. Evidently, the cloud thinning due to subsidence is less strong for the weaker subsidence cases. The difference among the simulations is about $3 \mathrm{~g} \mathrm{~m}^{-2} \mathrm{~h}^{-1}$ during the first part of the transition and slowly decreases with time. For the LWP tendencies due to radiation, entrainment and cloud base turbulent fluxes, shown in Fig. 6c, e and g respectively, the data do not show a clear trend due to the significant amount of noise. 

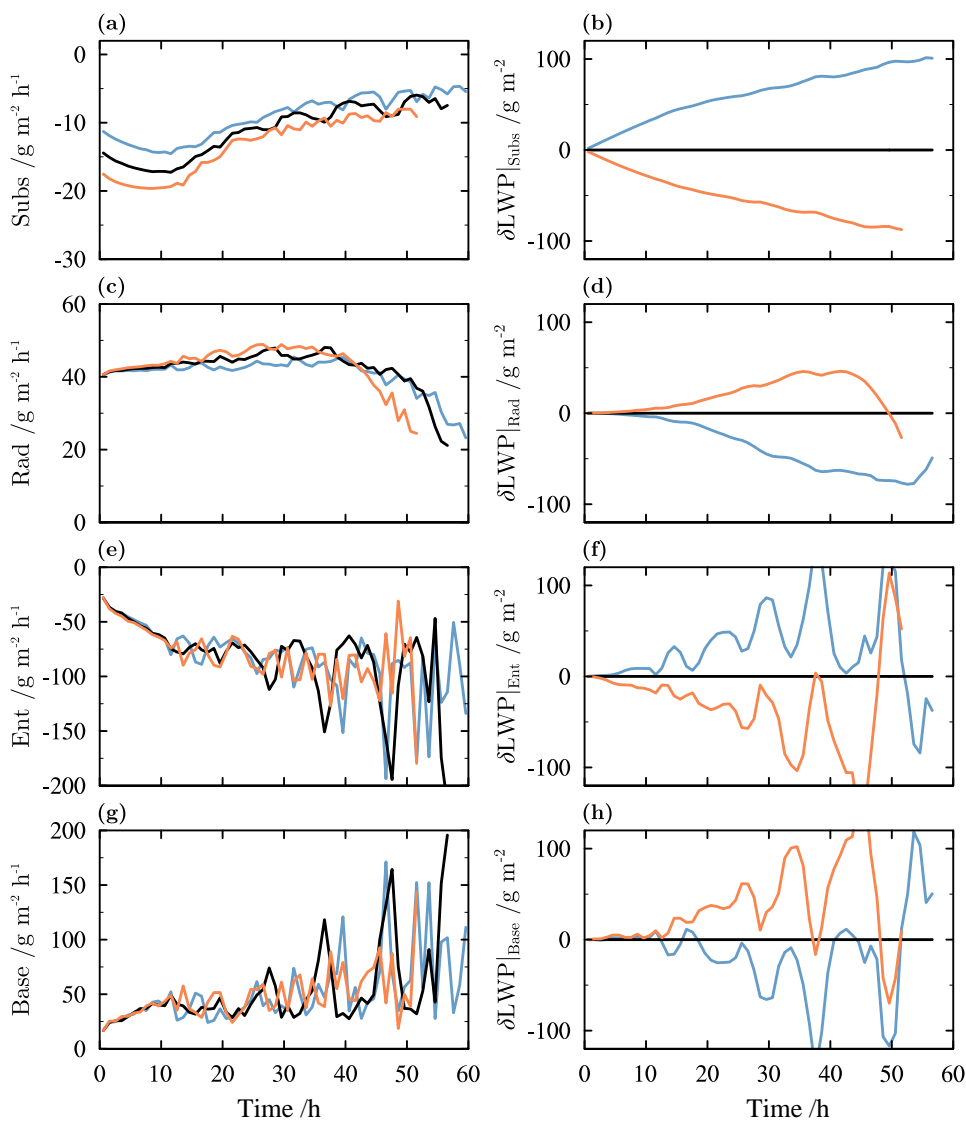

Figure 6. The LWP tendencies due to (a) subsidence, (c) radiation, (e) entrainment and (g) cloud base turbulent fluxes as a function of time for each of the sensitivity simulations. The LWP differences with the reference (black) due to each of these processes have been calculated according to Eq. (13) and are shown in panels (b), (d), (f) and (h), respectively. Colors according to the legend in Fig. 5a.

In order to obtain a clearer picture of how large the LWP differences caused by each of the individual processes are, the following steps are taken. First, the $-D z_{D}=$ $-4.5 \mathrm{~mm} \mathrm{~s}^{-1}$ simulation indicated by the black lines in Figs. 3-5 is chosen as a reference. Then, the differences with respect to this reference of the LWP tendency due to each process is determined. These differences are integrated in time to give the LWP difference among the simulations that is solely due to that process. So, for the subsidence term

$$
\begin{aligned}
\left.\delta \operatorname{LWP}\right|_{\text {Subs }}(t) & =\int_{0}^{t} \delta \operatorname{Subs}\left(t^{\prime}\right) \mathrm{d} t^{\prime} \\
& =\int_{0}^{t}\left[\operatorname{Subs}\left(t^{\prime}\right)-\operatorname{Subs}^{\mathrm{r}}\left(t^{\prime}\right)\right] \mathrm{d} t^{\prime},
\end{aligned}
$$

where $\delta$ denotes the difference of a variable with respect to the reference simulation that is denoted by a superscripted "r". Similarly, the LWP differences solely due to the Rad, Ent and Base terms in Eqs. (5) to (7) were calculated. The results are shown for each of the processes by the plots in the right hand column of Fig. 6.

The LWP difference caused solely by subsidence is shown in Fig. 6b. Consider the simulation indicated by the blue line, which has a weaker subsidence as compared to the reference simulation. The smaller cloud thinning tendency due to subsidence for this case causes a positive contribution to the LWP difference, $\delta$ LWP, that increases approximately linearly with time up to a value of about $100 \mathrm{~g} \mathrm{~m}^{-2}$.

The absorption of shortwave radiation by a stratocumulus layer increases with the LWP (Van der Dussen et al., 2013). So, as subsidence is weakened and the LWP increases, the absorption of shortwave radiation also increases. The net cloud thickening effect due to radiative cooling is therefore reduced. Hence, the LWP difference with the reference is negative for the weak subsidence simulation (Fig. 6d) and compensates for much of the LWP difference due to subsidence in the second part of the transition.

The LWP difference as a result of entrainment is less straightforward to understand. In the previous section, it was shown that the entrainment rate is largest for the weakest subsidence simulation. As entrainment causes drying and warm- 

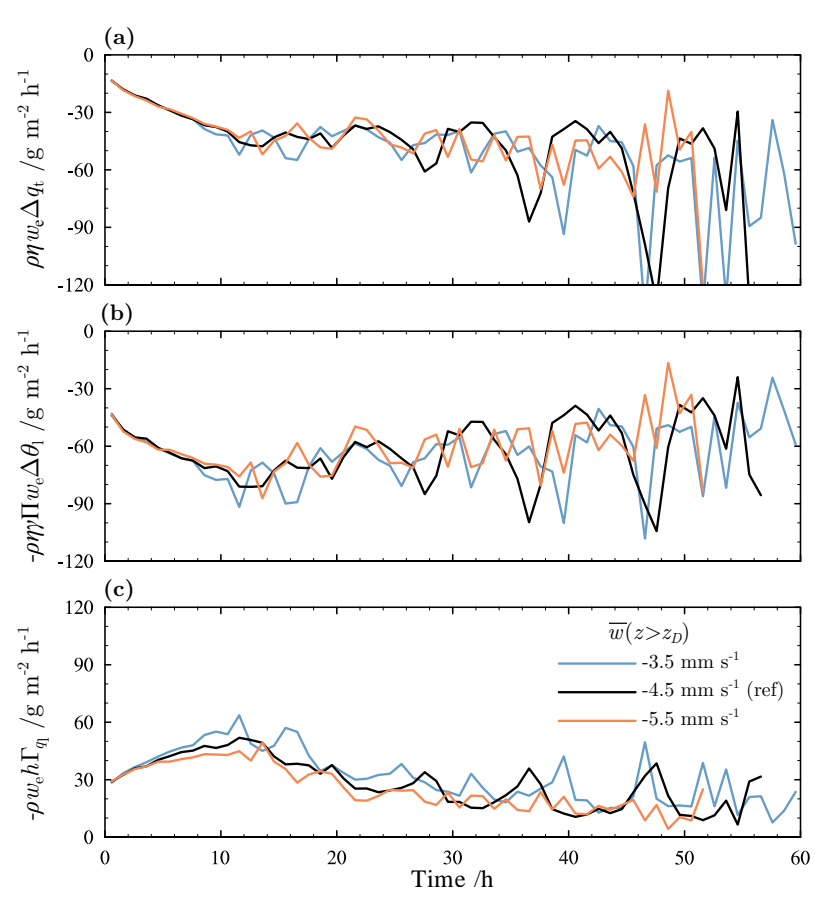

Figure 7. The LWP tendency due to entrainment split up into the three terms of Eq. (5): (a) entrainment drying, (b) entrainment warming and (c) cloud deepening due to entrainment.

ing of the stratocumulus layer, this higher entrainment velocity is expected to cause a negative contribution to $\delta$ LWP. However, Fig. 6f shows that it is the other way around: for the lowest subsidence case with the highest entrainment rate, the contribution of entrainment to $\delta$ LWP is positive.

Figure 7a-c individually show the three terms that together constitute the contribution of entrainment to the LWP tendency of Eq. (5). The last of these terms accounts for the deepening of the cloud layer due to entrainment (Fig. 7c), which according to Eq. (1) causes the inversion height and consequently the cloud top height to rise with time. It is important to note that the cloud layer thickness $h$ arises in the last term on the rhs of Eq. (5) due to the fact that the maximum cloud liquid water content is present at the cloud top, with its top value being approximately proportional to the cloud layer depth. If the cloud top of a deep cloud increases due to entrainment, this will yield a larger increase in the LWP than if the cloud top of a shallower cloud rises by the same distance. Therefore, this term increases with the cloud thickness $h$. For the weak subsidence simulation, $h$ is larger than for the reference simulation. This effect opposes the cloud thinning due to entrainment warming and drying, and causes the entrainment contribution to $\delta \mathrm{LWP}$ for the lowest subsidence case to be positive (i.e. with respect to the reference case).

Note furthermore that for weaker subsidence cases the boundary layer grows deeper, causing the cloud layer to be-

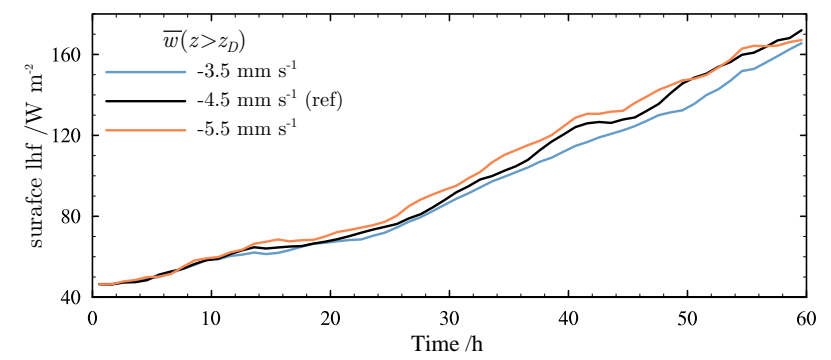

Figure 8. The surface latent heat flux as a function of time for the three sensitivity simulations.

come drier with respect to shallower boundary layers (Park et al., 2004; Wood and Bretherton, 2004). Hence, the magnitude of the inversion jump of humidity $\Delta q_{\mathrm{t}}$ decreases as subsidence is weakened as is shown in Fig. 5a. This decrease exceeds $0.5 \mathrm{~g} \mathrm{~kg}^{-1}$ at the end of the simulations, which causes the entrainment drying term in Fig. 7a to be practically identical for all three cases, despite the difference in the entrainment velocities.

Figure 6h shows the contribution of cloud base turbulent fluxes to $\delta$ LWP. The boundary layer is deepest for the weak subsidence simulation, which causes a slight reduction of the turbulent transport of humidity to the cloud layer. Moreover, Fig. 8 shows that the surface latent heat flux is reduced when the large-scale subsidence is reduced. Hence, the contribution of the cloud base fluxes to $\delta$ LWP is on average negative for the weak subsidence simulation indicated by the blue line.

From the comparison of Fig. 6f and h it is clear that the cloud base turbulent flux contribution to $\delta$ LWP is strongly anticorrelated with that of entrainment. The sum of both contributions is therefore almost zero. This can be understood as follows. Enhanced entrainment will also cause enhancement of the cloud base fluxes as the entrained air sinks downward through the cloud layer. Similarly, strong updrafts through cloud base lead to enhanced entrainment when the updraft reaches and overshoots the inversion layer. Such anticorrelated behavior causes the cancellation of the entrainment and cloud base terms in the sensitivity experiments. In other words, the net effect of these turbulent fluxes to the LWP difference among the cases is very small. The LWP differences in Fig. 3b are therefore mainly due to the direct effect of large-scale subsidence on the LWP tendency and the subsequent change of the absorption of shortwave radiation.

\section{Conclusions}

Several studies have shown that as a result of warming of the climate the Hadley circulation might weaken, leading to a weakening of the large-scale subsidence in the subtropical stratocumulus areas. Several modeling studies (Svensson et al., 2000; Sandu and Stevens, 2011) and recent observa- 
tional evidence (Myers and Norris, 2013) suggest that such a decrease can lead to thicker and more persistent stratocumulus clouds.

To investigate how the large-scale subsidence affects stratocumulus layers, a method is applied in the current study to analyze the individual contributions of five different physical processes to the LWP tendency of an approximately adiabatic stratocumulus layer. As an illustration of the use of this method, it was first applied to LES results of the ASTEX stratocumulus transition (Van der Dussen et al., 2013). The results show among others that subsidence tends to reduce the LWP by pushing down the cloud top, but the resulting tendency is small at only a few $\mathrm{g} \mathrm{m}^{-2} \mathrm{~h}^{-1}$. Longwave radiative cooling tends to increase the LWP by on average $60 \mathrm{~g} \mathrm{~m}^{-2} \mathrm{~h}^{-1}$, while the absorption of shortwave radiation during the day almost completely diminishes the net radiative effect. Entrainment dries and warms the cloud layer resulting in a strong cloud thinning effect. The analysis shows that this cloud thinning contribution becomes stronger as the transition progresses. The transport of humidity toward the cloud layer by turbulent fluxes counteracts this drying, causing a significant positive effect on the LWP tendency.

Despite the relatively small contribution of large-scale subsidence to the LWP tendency, more idealized sensitivity simulations show that decreasing the subsidence velocity extends the lifetime of the stratocumulus layer. Moreover, it causes the LWP to be significantly higher throughout the entire transition. The thicker stratocumulus layer in the weak subsidence cases tends to absorb more solar radiation, which partly offsets the LWP difference due to subsidence in the second part of the simulations.

It was shown that a weakening of the large-scale subsidence causes enhanced entrainment that amplifies the differences of the inversion height among the simulations. Counterintuitively, this higher entrainment rate does not result in a stronger cloud thinning tendency with respect to the reference simulation. This is mainly explained by an increase of the cloud thickness as well as by a reduction of the magnitude of $\Delta q_{\mathrm{t}}$, the inversion jump for humidity.

The cloud thickening contribution of the cloud base turbulent fluxes decreases somewhat for the weaker subsidence cases as a result of the greater boundary layer depth. This decrease is strongly anticorrelated to the LWP increase as a result of entrainment, such that the total contribution of the turbulent fluxes to the LWP difference among the cases is negligible.

The results of the current study suggest that it is likely that a weakening of the large-scale subsidence in the subtropics due to the weakening of the Hadley circulation in a future climate increases the average LWP as well as the occurrence of subtropical stratocumulus clouds.
Acknowledgements. We thank the two anonymous reviewers whose suggestions helped to improve the manuscript. The investigations were done as part of the European Union CLoud Intercomparison, Process Study \& Evaluation (EUCLIPSE) project, funded under Framework Program 7 of the European Union. The work was sponsored by the National Computing Facilities Foundation (NCF) for the use of supercomputer facilities.

Edited by: H. Wang

\section{References}

Albrecht, B. A., Fairall, C. W., Thomson, D. W., White, A. B., Snider, J. B., and Schubert, W. H.: Surface-based remote sensing of the observed and the Adiabatic liquid water content of stratocumulus clouds, Geophys. Res. Lett., 17, 89-92, doi:10.1029/GL017i001p00089, 1990.

Albrecht, B. A., Bretherton, C. S., Johnson, D., Scubert, W. H., and Frisch, A. S.: The Atlantic Stratocumulus Transition Experiment-ASTEX, B. Am. Meteorol. Soc., 76, 889-904, doi:10.1175/1520-0477(1995)076<0889:TASTE>2.0.CO;2, 1995.

Arakawa, A.: Modelling clouds and cloud processes for use in climate models, Global Atmospheric Research Program Publication Series, no. 16 (ICSU/WMO); The Physical Basis of Climate and Climate Modeling, 183-197, 1975.

Blossey, P. N. and Durran, D. R.: Selective monotonicity preservation in scalar advection, J. Comput. Phys., 227, 5160-5183, 2008.

Böing, S. J.: The Interaction between deep convective clouds and their environment, $\mathrm{PhD}$ thesis, Delft University of Technology, Delft, 133 pp., doi:10.4233/uuid:aa9e6037-b9cb-4ea09eb0-a47bf1dfc940, 2014.

Bretherton, C. S.: Insights into low-latitude cloud feedbacks from high-resolution models, Philos. T. R. Soc. A, 373, 26438280, doi:10.1098/rsta.2014.0415, 2015.

Bretherton, C. S. and Blossey, P. N.: Low cloud reduction in a greenhouse-warmed climate: Results from Lagrangian LES of a subtropical marine cloudiness transition, J. Adv. Model. Earth Syst., 6, 91-114, doi:10.1002/2013MS000250, 2014.

Bretherton, C. S., Austin, P., and Siems, S. T.: Cloudiness and Marine Boundary Layer Dynamics in the ASTEX Lagrangian Experiments. Part II: Cloudiness, Drizzle, Surface Fluxes, and Entrainment, J. Atmos. Sci., 52, 2724-2735, doi:10.1175/15200469(1995)052<2724:CAMBLD>2.0.CO;2, 1995.

Bretherton, C. S., Krueger, S. K., Wyant, M. C., Bechtold, P., Van Meijgaard, E., Stevens, B., and Teixeira, J.: A GCSS Boundary-Layer Cloud Model Intercomparison Study Of The First ASTEX Lagrangian Experiment, Bound.-Lay. Meteorol., 93, 341-380, doi:10.1023/A:1002005429969, 1999.

Bretherton, C. S., Blossey, P. N., and Jones, C. R.: Mechanisms of marine low cloud sensitivity to idealized climate perturbations: A single-LES exploration extending the CGILS cases, J. Adv. Model. Earth Syst., 5, 316-337, doi:10.1002/jame.20019, 2013. 
Carman, J. K., Rossiter, D. L., Khelif, D., Jonsson, H. H., Faloona, I. C., and Chuang, P. Y.: Observational constraints on entrainment and the entrainment interface layer in stratocumulus, Atmos. Chem. Phys., 12, 11135-11152, doi:10.5194/acp-1211135-2012, 2012.

Ciesielski, P. E., Schubert, W. H., and Johnson, R. H.: Diurnal Variability of the Marine Boundary Layer during ASTEX, J. Atmos. Sci., 58, 2355-2376, doi:10.1175/15200469(2001)058<2355:DVOTMB >2.0.CO;2, 2001.

De Roode, S. R. and Duynkerke, P. G.: Observed Lagrangian Transition of Stratocumulus into Cumulus during ASTEX: Mean State and Turbulence Structure, J. Atmos. Sci., 54, 2157-2173, doi:10.1175/1520-0469(1997)054<2157:OLTOSI>2.0.CO;2, 1997.

De Roode, S. R., Siebesma, A. P., Gesso, S. D., Jonker, H. J. J., Schalkwijk, J., and Sival, J.: A mixed-layer model study of the stratocumulus response to changes in largescale conditions, J. Adv. Model. Earth Syst., 6, 1256-1270, doi:10.1002/2014MS000347, 2014.

De Roode, S. R., Sandu, I., van der Dussen, J. J., Ackerman, A. S., Blossey, P., Jarecka, D., Lock, A., Siebesma, A. P., and Stevens, B.: Large eddy simulations of EUCLIPSE/GASS Lagrangian stratocumulus to cumulus transitions: Mean state, turbulence and decoupling, J. Atmos. Sci., submitted, 2016.

Deardorff, J. W.: Stratocumulus-capped mixed layers derived from a three-dimensional model, Bound.-Lay. Meteorol., 18, 495-527, doi:10.1007/BF00119502, 1980.

Duynkerke, P. G., Jonker, P. J., Chlond, A., Van Zanten, M. C., Cuxart, J., Clark, P., Sanchez, E., Martin, G., Lenderink, G., and Teixeira, J.: Intercomparison of Threeand one-Dimensional Model Simulations and Aircraft Observations of Stratocumulus, Bound.-Lay. Meteorol., 92, 453-487, doi:10.1023/A:1002006919256, 1999.

Emanuel, K. A.: Atmospheric convection, Oxford University Press, 1994.

Ghonima, M. S., Norris, J. R., Heus, T., and Kleissl, J.: Reconciling and Validating the Cloud Thickness and Liquid Water Path Tendencies Proposed by R. Wood and J. J. van der Dussen et al., J. Atmos. Sci., 72, 2033-2040, doi:10.1175/JAS-D-14-0287.1, 2015.

Held, I. M. and Soden, B. J.: Robust Responses of the Hydrological Cycle to Global Warming, J. Climate, 19, 5686-5699, doi:10.1175/JCLI3990.1, 2006.

Heus, T., van Heerwaarden, C. C., Jonker, H. J. J., Pier Siebesma, A., Axelsen, S., van den Dries, K., Geoffroy, O., Moene, A. F., Pino, D., de Roode, S. R., and Vilà-Guerau de Arellano, J.: Formulation of the Dutch Atmospheric Large-Eddy Simulation (DALES) and overview of its applications, Geosci. Model Dev., 3, 415-444, doi:10.5194/gmd-3-415-2010, 2010.

Iacono, M. J., Delamere, J. S., Mlawer, E. J., Shephard, M. W., Clough, S. A., and Collins, W. D.: Radiative forcing by long-lived greenhouse gases: Calculations with the AER radiative transfer models, J. Geophys. Res., 113, D13103, doi:10.1029/2008JD009944, 2008.

Jiang, G.-S. and Shu, C.-W.: Efficient Implementation of Weighted ENO Schemes, J. Comput. Phys., 126, 202-228, 1996.

Jones, C. R., Bretherton, C. S., and Blossey, P. N.: Fast stratocumulus time scale in mixed layer model and large eddy simulation, J. Adv. Model. Earth Syst., 6, 206-222, doi:10.1002/2013MS000289, 2014.

Kogan, Y.: A Cumulus Cloud Microphysics Parameterization for Cloud-Resolving Models, J. Atmos. Sci., 70, 1423-1436, doi:10.1175/JAS-D-12-0183.1, 2013.

Myers, T. A. and Norris, J. R.: Observational Evidence That Enhanced Subsidence Reduces Subtropical Marine Boundary Layer Cloudiness, J. Climate, 26, 7507-7524, doi:10.1175/JCLI-D-1200736.1, 2013.

Nicholls, S. and Turton, J. D.: An observational study of the structure of stratiform cloud sheets: Part II. Entrainment, Q. J. Roy. Meteorol. Soc., 112, 461-480, doi:10.1002/qj.49711247210, 1986.

Park, S., Leovy, C. B., and Rozendaal, M. A.: A New Heuristic Lagrangian Marine Boundary Layer Cloud Model, J. Atmos. Sci., 61, 3002-3024, doi:10.1175/JAS-3344.1, 2004.

Randall, D. A., Coakley, J. A., Lenschow, D. H., Fairall, C. W., and Kropfli, R. A.: Outlook for Research on Subtropical Marine Stratification Clouds, B. Am. Meteorol. Soc., 65, 1290-1301, doi:10.1175/1520-0477(1984)065<1290:OFROSM>2.0.CO;2, 1984.

Sandu, I. and Stevens, B.: On the Factors Modulating the Stratocumulus to Cumulus Transitions, J. Atmos. Sci., 68, 1865-1881, doi:10.1175/2011JAS3614.1, 2011.

Svensson, G., Tjernström, M., and Koračin, D.: The Sensitivity Of A Stratocumulus Transition: Model Simulations Of The ASTEX First Lagrangian, Bound.-Lay. Meteorol., 95, 57-90, doi:10.1023/A:1002434314651, 2000.

Van der Dussen, J. J., de Roode, S. R., Ackerman, A. S., Blossey, P. N., Bretherton, C. S., Kurowski, M. J., Lock, A. P., Neggers, R. A. J., Sandu, I., and Siebesma, A. P.: The GASS/EUCLIPSE model intercomparison of the stratocumulus transition as observed during ASTEX: LES results, J. Adv. Model. Earth Syst., 5, 483-499, doi:10.1002/jame.20033, 2013.

Van der Dussen, J. J., de Roode, S. R., and Siebesma, A. P.: Factors Controlling Rapid Stratocumulus Cloud Thinning, J. Atmos. Sci., 71, 655-664, doi:10.1175/JAS-D-13-0114.1, 2014.

Van der Dussen, J. J., de Roode, S. R., Gesso, S. D., and Siebesma, A. P.: An LES model study of the influence of the free tropospheric thermodynamic conditions on the stratocumulus response to a climate perturbation, J. Adv. Model. Earth Syst., 7, 670-691, doi:10.1002/2014MS000380, 2015.

vanZanten, M. C., Duynkerke, P. G., and Cuijpers, J. W. M.: Entrainment Parameterization in Convective Boundary Layers, J. Atmos. Sci., 56, 813-828, doi:10.1175/15200469(1999)056<0813:EPICBL>2.0.CO;2, 1999.

Vecchi, G. A. and Soden, B. J.: Global Warming and the Weakening of the Tropical Circulation, J. Climate, 20, 4316-4340, doi10.1175/JCLI4258.1, 2007.

Wood, R.: Cancellation of Aerosol Indirect Effects in Marine Stratocumulus through Cloud Thinning, J. Atmos. Sci., 64, 26572669, doi:10.1175/JAS3942.1, 2007.

Wood, R. and Bretherton, C. S.: Boundary Layer Depth, Entrainment, and Decoupling in the Cloud-Capped Subtropical and Tropical Marine Boundary Layer, J. Climate, 17, 3576-3588, doi:10.1175/1520-0442(2004)017<3576:BLDEAD>2.0.CO;2, 2004.

Wyant, M. C., Bretherton, C. S., Rand, H. A., and Stevens, D. E.: Numerical Simulations and a Conceptual Model of the Stratocu- 
mulus to Trade Cumulus Transition, J. Atmos. Sci., 54, 168-192, doi:10.1175/1520-0469(1997)054<0168:NSAACM>2.0.CO;2, 1997.
Yamaguchi, T., Randall, D. A., and Khairoutdinov, M. F.: Cloud Modeling Tests of the ULTIMATE-MACHO Scalar Advection Scheme, Mon. Weather Rev., 139, 3248-3264, doi:10.1175/MWR-D-10-05044.1, 2011. 